Check for updates

Cite this: RSC Adv., 2019, 9, 10626

Received 29th January 2019

Accepted 20th March 2019

DOI: $10.1039 / c 9 r a 00779 b$

rsc.li/rsc-advances

\section{Optimised thermally driven molecular stability of an SCO metal complex for TEC Seebeck generation enhancement}

Megat Muhammad Ikhsan Megat Hasnan, ${ }^{2}$ Suhana Mohd Said, (DD *a Mohd Faizul Mohd Sabri, ${ }^{\text {b }}$ Siti Amira Mat Hussin, ${ }^{\mathrm{C}}$ Norbani Abdullah, ${ }^{\mathrm{c}}$ Nik Muhd Jazli Nik Ibrahim, ${ }^{a}$ Yuzuru Miyazaki, ${ }^{d}$ Mohd Faiz Mohd Salleh ${ }^{a}$ and Noraisyah Mohd Shah (iD ${ }^{\text {a }}$

The thermoelectricity effect allows the generation of electrical potential in an electrolyte upon application of a thermal gradient. In the previous work, the spin crossover effect in metal complexes was shown to be beneficial for generating a high Seebeck coefficient due to the high entropy associated with the conformational change accompanying the spin state change. In this study, we examine the diamagnetic stability of a spin crossover material through optimisation of the ligand chain length. We show that the diamagnetic stability of the spin crossover material can enhance the thermoelectrochemical Seebeck effect through ligand optimisation of the octahedral structure. The increase of carbon chain length from $\mathrm{C}_{14}$ to $\mathrm{C}_{16}$ in the long alkyl chain of the $\mathrm{N}$-donor ligand increased Seebeck generation in a Co(II)L16 complex to 1.94-fold that of a previously studied paramagnetic Co complex, and in a Fe(III)L16 complex to 3.43-fold that of a less diamagnetic Fe complex. We show with DSC studies of an Fe based octahedral complex that an endothermic absorption accompanies the spin crossover transition, which enhances the Seebeck coefficient of this metal complex. Thus, we can correlate the diamagnetic stabilisation with temperature. We therefore indicate a molecular design strategy for optimisation of a spin crossover metal complex.

\section{Introduction}

The thermoelectric (TE) phenomenon is shown by a solid state electronic material that converts a thermal gradient into electricity. This TE behaviour is also observed in thermoelectrochemical cells (TECs) which consist of two inert electrodes and an active redox material. ${ }^{\mathbf{1}}$ The active redox material is dissolved in a solvent or ionic liquid. A temperature difference $(\Delta T)$ arises between the hot electrode and cold electrode which causes an imbalance of the redox reactions and generates an electromotive force $(\Delta V) .^{2-8}$

Recently, spin crossover (SCO) materials have been found to enhance the TE properties of several complexes. ${ }^{9-11}$ SCO complexes are attractive and valuable materials for stimuli (thermal-light) responsive devices, such as photocatalytic energy harvesting devices and photosensors. ${ }^{12-17}$ The highest

${ }^{a}$ Electrical Engineering Department, Engineering Faculty, Universiti Malaya, 50603 Kuala Lumpur, Malaysia.E-mail: smsaid@um.edu.my

${ }^{b}$ Mechanical Engineering Department, Engineering Faculty, Universiti Malaya, 50603 Kuala Lumpur, Malaysia

${ }^{c}$ Chemistry Department, Science Faculty, Universiti Malaya, 50603 Kuala Lumpur, Malaysia

${ }^{d}$ Department of Applied Physic, Graduate School of Engineering, Tohoku University, 6-6-04, Aramaki Aza Aoba Aoba-ku, Sendai, Miyagi 980-8579, Japan
Seebeck coefficients $\left(S_{\mathrm{e}}\right)$ so far observed accompanied the change in the spin state of a $\mathrm{Co}^{2+/ 3+}(\mathrm{bpy})_{3}\left(\mathrm{NTf}_{2}\right)_{2 / 3}$ redox couple in a 3 methoxypropionitrile (MPN) solvent $\left(2.19 \mathrm{mV} \mathrm{K}^{-1}\right.$ for a $0.01 \mathrm{M}$ solution)..$^{18}$ This was ascribed to a large entropy change $(\Delta S)$, which arose because the bond lengths for an octahedral complex in the high spin (HS) state are longer (weaker) compared to those of the low spin (LS) state. A larger $\Delta S$ results in a higher $S_{\mathrm{e}}$ value. This electrochemical Seebeck effect in TEC is due to the difference in the entropy values (redox reaction entropy) at the hot and cold sides of the electrode. ${ }^{19}$ The reaction entropy during the redox reaction is related to the ratio of the potential difference between the electrodes and the temperature difference, as expressed in eqn (1)

$$
S_{\mathrm{e}}=\frac{\Delta V}{\Delta T}=\frac{\Delta S_{\text {reaction }}}{n F}
$$

where $n$ is number of electrons involved in the redox reaction and $F$ is Faraday constant. Based on Born's model, the entropy reaction $\Delta S_{\text {reaction }}$ is expressed as shown in eqn $(2)^{\mathbf{8 , 2 0 , 2 1}}$

$$
\Delta S_{\text {reaction }}=-\frac{e^{2} N}{2 \varepsilon T}\left(\frac{\mathrm{d} \ln \varepsilon}{\mathrm{d} \ln T}\right)\left(\frac{Z_{\mathrm{ox}}^{2}}{r_{\mathrm{ox}}}-\frac{Z_{\mathrm{red}}{ }^{2}}{r_{\text {red }}}\right)
$$

where $\varepsilon$ is the dielectric constant, $Z_{\text {ox }}$ and $Z_{\text {red }}$ are the valence charges of the oxidant and reductant, respectively, $r_{\text {ox }}$ and $r_{\text {red }}$ are the corresponding radii, $e$ is the electronic charge and $N$ is 
Avogadro's constant. The Seebeck coefficient can be increased by increasing the entropy, through increasing the differences in molecular radii and valence charges of the oxidised and reduced species. SCO materials are particularly interesting as the materials possess distinct HS and LS states which can be correlated to significant changes in the molecular conformations., ${ }^{2,8}$ In this case, the spin state transition is driven by temperature. The entropy difference based on SCO $\left(\Delta S_{\text {spin }}\right)$ can be expressed by the equation:

$$
\Delta S_{\mathrm{spin}}=R \ln \left[(2 S+1)_{\mathrm{HS}} /(2 S+1)_{\mathrm{LS}}\right]
$$

Octahedral complexes of first-row transition-metal ions with labile electronic configurations $\left(\mathrm{d}^{4}-\mathrm{d}^{7}\right)$ and ligands of intermediate field strengths have been studied previously to drive the SCO effect. These types of complex are central to high stability diamagnetic complexes that can enhance Seebeck generation from temperature differences in TECs. ${ }^{9-11}$ Fe complexes have been found to produce the highest Seebeck coefficients through agglomeration in the form of spherical micelles (average micelles diameter $100 \mathrm{~nm}$ ) as shown in Fig. 1. The trapped charge carriers within the micelles enhance the diffusion activity thus enhancing both Seebeck and ionic conductivity compared to the active redox couple in the absence of agglomeration. ${ }^{9}$

With respect to octahedral complexes, we expect the stability of an octahedral structure to be described by the Jahn-Teller theorem, in which the complex will suffer weak and strong JahnTeller effects if the electrons are unevenly occupied in the $\mathrm{T}_{2 \mathrm{~g}}$ and $\mathrm{E}_{\mathrm{g}}$ orbitals, respectively, as shown in Fig. 2. If the $\mathrm{T}_{2 \mathrm{~g}}$ and $\mathrm{E}_{\mathrm{g}}$ orbitals are evenly occupied, there will be no Jahn-Teller effect.

In this study, we continue our investigation by optimizing the ligand structure to design highly stable diamagnetic

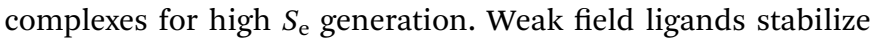

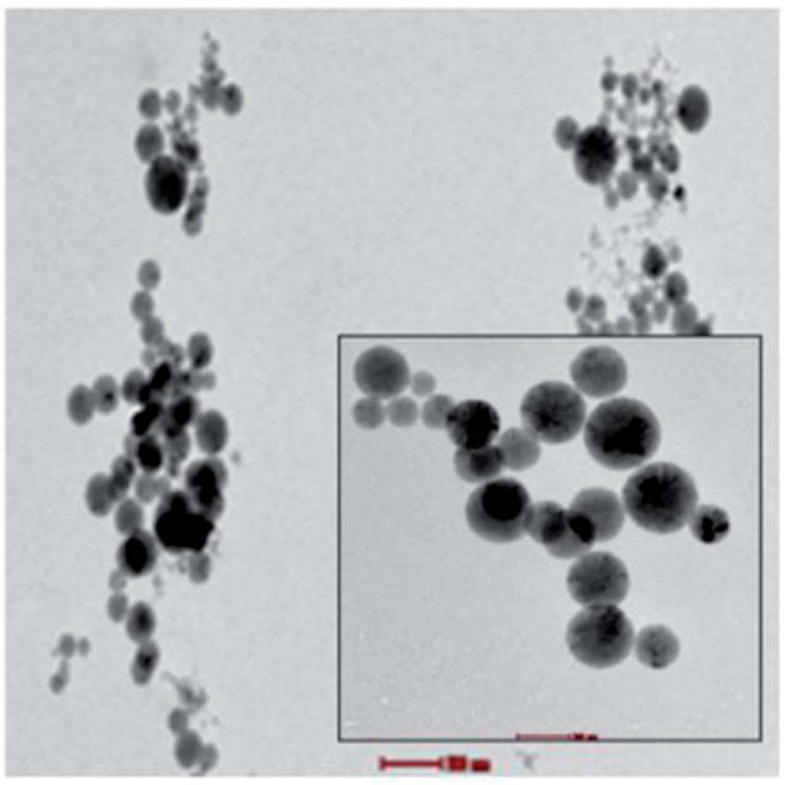

Fig. 1 Cyro TEM analysis of micelles of $0.1 \mathrm{mM}$ Fe complex that can trap the $\mathrm{KI}-\mathrm{KI}_{3}$ redox active electrolyte in the high polarity MPN solvent.

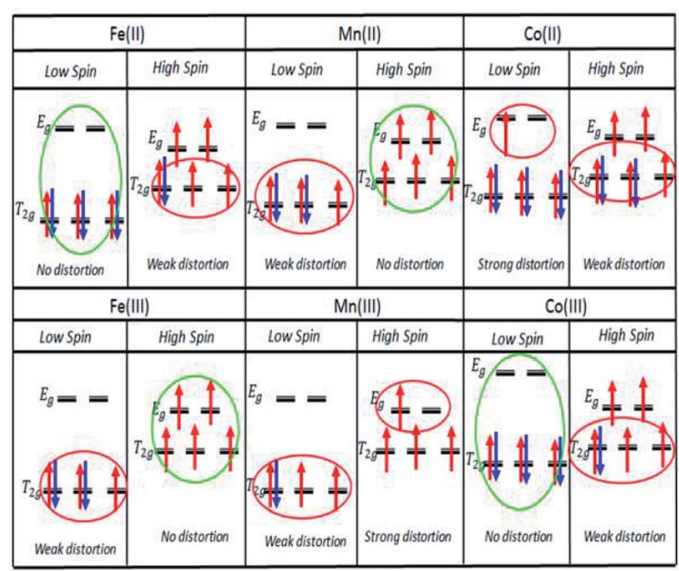

Fig. 2 Jahn-Teller distortion effects for LS/HS states of Fe, Mn, and $\mathrm{Co}^{2+/ 3+}$ ions.

the HS (maximum spin multiplicity) ground state, whilst strong field ligands stabilize the LS (minimum multiplicity) ground state. The coordinate bonds in the HS complexes are longer (weaker) than those in the LS complexes. The strategy for enhancing the Seebeck and power densities for TECs involves increasing the ligand field strength by increasing the ligand carbon chain length number in our previous octahedral structure. A longer chain length is expected to improve diamagnetic stability and thermal stability, ${ }^{9}$ and we use a neutral $\mathrm{N}$-donor ligand $\left(\mathrm{C}_{n}=\mathrm{C}_{14}\right)$ and benzoate as the counter ion. In order to maintain an intermediate ligand field strength in the complexes to drive the reverse SCO effect, we use the maximum carbon chain length $\left(\mathrm{C}_{16}\right)$ using a concept proposed by Hayami. ${ }^{22} \mathrm{He}$ proposed that the long alkyl chain could produce a "hook" effect by which it could pull out the ligand from the metal centre in the HS state at room temperature. Upon application of temperature, the van der Waals forces between the alkyl chains are expected to break, allowing for a closer approach of the ligand to the metal centre to drive a stable LS state.

In this paper, the following hypotheses will be investigated:

(a) An increased ligand carbon chain length in the octahedral structure design causes a reverse SCO effect with increasing temperature.

(b) The spin state transition of the octahedral metal complex determines the stability of the complex.

(c) Ultimately, the SCO effect detects stability as a function of temperature based on the Jahn-Teller distortion.

(d) The optimum Seebeck generation is for an $\mathrm{Fe}$ ion complex. This is greater than those for $\mathrm{Mn}$ and $\mathrm{Co}$ ion complexes since Fe ions should not suffer weak or strong distortions due to evenly occupied orbitals in the transitions for normal SCO (Fe(II)LS to Fe(III)HS) and reverse SCO (Fe(III)HS to $\mathrm{Fe}(\mathrm{II}) \mathrm{LS}$ ), as shown in Fig. 3.

\section{Experimental}

\section{Ligand (L16) preparation}

A mixture of $4-\mathrm{HOC}_{5} \mathrm{H}_{4} \mathrm{~N}(5.01 \mathrm{~g}, 52.70 \mathrm{mmol}), \mathrm{K}_{2} \mathrm{CO}_{3}(17.28 \mathrm{~g}$, $125.10 \mathrm{mmol})$ and $\mathrm{KI}(0.33 \mathrm{~g}, 2.00 \mathrm{mmol})$ in DMF $(200 \mathrm{~mL})$ was 


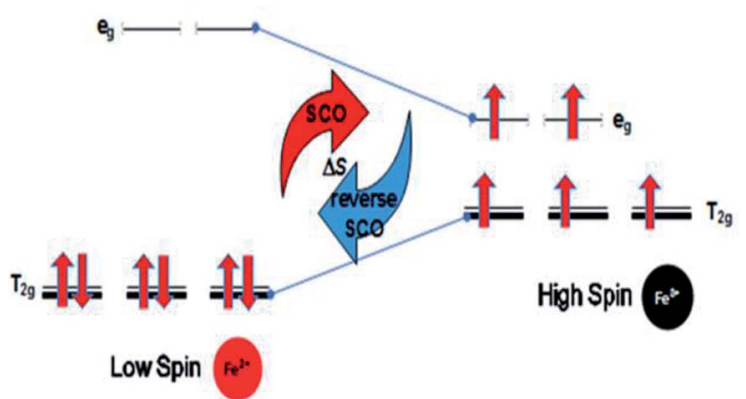

Fig. 3 Ideal stability of the Fe ion complex for high Seebeck generation.

stirred vigorously in a round bottomed flask at room temperature. $\mathrm{CH}_{3}\left(\mathrm{CH}_{2}\right)_{15} \mathrm{Br}(15.25 \mathrm{~g}, 50.0 \mathrm{mmol})$ was added portion-wise to the magnetically stirred solution. The reaction mixture was then refluxed for 72 hours, and left to cool at room temperature overnight. Distilled water was added into the mixture and it was left overnight. A yellow solid formed, which was collected by suction filtration and washed with distilled water. The product was a white powder and its yield was $12.98 \mathrm{~g}$ (81.27\%). The structure of the ligand $\mathbf{L 1 6}$ was ascertained using CHN elemental analyses, nuclear magnetic resonance ( $\left.{ }^{1} \mathrm{H}-\mathrm{NMR}\right)$ spectroscopy and Fourier transform infrared (FTIR) spectroscopy.

\section{Preparation of SCO complexes}

A $20 \mathrm{~mL}$ solution of $\mathbf{L 1 6}$ in $\mathrm{CHCl}_{3}$ was prepared and then it was added portion-wise to three different magnetically stirred suspensions: $\quad \mathrm{Co}\left(\mathrm{C}_{6} \mathrm{H}_{5} \mathrm{COO}\right)_{2}($ cyclam $)\left(\mathrm{C}_{6} \mathrm{H}_{5} \mathrm{COO}\right), \quad \mathrm{Fe}\left(\mathrm{C}_{6} \mathrm{H}_{5^{-}}\right.$ $\mathrm{COO})_{2}($ cyclam $) \cdot 2 \mathrm{H}_{2} \mathrm{O}$ and $\mathrm{Mn}\left(\mathrm{C}_{6} \mathrm{H}_{5} \mathrm{COO}\right)_{2}($ cyclam $) \cdot 7 \mathrm{H}_{2} \mathrm{O}$.

The structural formulae of the prepared complexes were deduced using a combination of carbon, hydrogen and nitrogen (CHN) elemental analyses, FTIR, ${ }^{1} \mathrm{H}-\mathrm{NMR}$, ultra violet (UV-vis) spectroscopy and superconducting quantum interference device (SQUID) magnetometry.

The prepared complexes were then dissolved in either DMSO (Mn and Co complexes) or MPN (Fe complexes) to form $1 \mathrm{mM}$ TEC solutions in the presence of $1 \mathrm{mM} \mathrm{KI}-\mathrm{KI}_{3}$ as a redox active material and 0.1 M TBATFB as the supporting electrolyte.

\section{Structural analyses}

The CHN elemental analyses were recorded on a PerkinElmer PE 2400 Series II CHNS/O analyser and Thermo-Finnigan Flash EA 110. A small amount of each sample $(1.5-2.0 \mathrm{mg})$ was placed in a tin capsule with dimensions of $5 \mathrm{~mm} \times 8 \mathrm{~mm}$. The weighed samples were wrapped and then folded into smaller pieces before being placed in the analyser.

The FTIR spectra were recorded neat from $4000-400 \mathrm{~cm}^{-1}$ at room temperature on a PerkinElmer 400 FT-IR/FT-IR Spectrometer with a Pike 22107 Technologies GladiATR attachment.

\section{Thermal analysis}

The thermal stabilities of the complexes were determined by thermogravimetry analysis (TGA). The thermogravimetric traces were recorded using a Pyris Diamond TG/DTA PerkinElmer instrument.
An empty ceramic pan was placed in the holder, and then tarred. Each sample (about $4 \mathrm{mg}$ ) was loaded onto the pan and its weight was recorded. The spectra were recorded in the temperature range 303-1173 K under $\mathrm{N}_{2}$ at a flow rate of $293 \mathrm{~K} \mathrm{~min}^{-1}$.

The differential scanning calorimetry (DSC) was performed on a METTLER TOLEDO DSC 822. Each sample (about $4.0 \mathrm{mg}$ ) was weighed in an aluminium pan by using an external microbalance and then it was placed inside the DSC heating stage. The scans were recorded for one heating and cooling cycle in the temperature range of 298-390 K. The heating and cooling rates were $5{ }^{\circ} \mathrm{C} \mathrm{min}^{-1}$.

\section{Magnetic analysis}

The magnetic properties of the complexes can be inferred by ${ }^{1} \mathrm{H}-$ NMR spectroscopy. Diamagnetic complexes are NMR active, and therefore produce well-resolved ${ }^{1} \mathrm{H}$-NMR signals. Paramagnetic complexes are partially NMR active, and therefore do not produce well-resolved ${ }^{1} \mathrm{H}$-NMR signals (peaks are broadened and some peaks are missing) due to the unfavourable electronic relaxation times.

In order to investigate the magnetic properties of the complexes, SQUID magnetometer analysis was also used to measure magnetic susceptibility values as a function of temperature.

\section{UV-vis spectroscopy}

The UV-vis spectra were recorded from $1000 \mathrm{~nm}$ to $300 \mathrm{~nm}$ on a Shimadzu UV-vis NIR 3600 spectrophotometer. An exactly known amount of each sample (about $5 \mathrm{mg}$ ) was dissolved in $10 \mathrm{~mL}$ solvent and then placed into a $1 \mathrm{~cm}$ quartz cuvette. The absorbance spectrum was recorded against the solvent background with a fast scan rate. The molar absorptivity $(\varepsilon)$ was calculated using the Beer-Lambert law as expressed in eqn (3)

$$
A=\varepsilon c l
$$

where $A$ is absorbance, $c$ is molarity, and $l$ is the path length ( 1 $\mathrm{cm})$.

\section{Non-isothermal Seebeck measurement}

The Seebeck coefficients for the complexes were measured using a non-isothermal two beaker experimental setup ${ }^{1,2,23-29}$ for three cycles in which $T_{\text {cold }}$ was $305 \mathrm{~K}$ and $T_{\text {hot }}$ was $300-350 \mathrm{~K}$. The temperature for every measurement was confirmed using a thermocouple type-K. The complexes $(1 \mathrm{mM})$ were dissolved in $10 \mathrm{~mL}$ of DMSO solvent (Co and Mn) or $10 \mathrm{~mL}$ of MPN (Fe) in the presence of $0.1 \mathrm{M}$ TBATFB as the supporting electrolyte and $1 \mathrm{mM} \mathrm{KI}-\mathrm{KI}_{3}$ as the redox couple. The temperature gradient was confirmed using a thermocouple type-K.

\section{Power density measurement}

The power measurements were made using a high input impedance digital multimeter (Agilent 34461A) and a resistor box with a resistance range of $1 \Omega$ to $10 \mathrm{M} \Omega$. The samples were filled into fabricated TEC devices and thermocouples were used as the temperature probes to confirm the temperature gradient. 
The power generated using Pt as the active working electrode $\left(\right.$ area $=1 \mathrm{~cm}^{2}$ ) at the hot side and the cold side was measured in steady state conditions with different temperature gradients. The lower electrode was heated using a ceramic heater while the upper electrode was exposed to the air flow from a fan for a natural air convection heat sink. The temperatures were measured using a type-K thermocouple that measured the temperature of the wafer surface at both the cold side and the hot side. All measurements were taken over 5 cycles.

\section{TEC device fabrication}

In this study, we measured the power density for the complex which possessed the highest Seebeck coefficient in the TEC devices. The TEC devices were fabricated using micromachining technology using the process flow shown in Fig. 4. Silicon wafer substrates $\left(2 \times 2 \mathrm{~cm}^{2}\right)$ of $300 \mu \mathrm{m}$ thickness were used as the base material due to their high thermal conductivity $\left(148 \mathrm{~W} \mathrm{~m}^{-1} \mathrm{~K}^{-1}\right)$ for fast heat transfer and fast steady state response. SU-8 dry film resist, which has low thermal conductivity $\left(0.2 \mathrm{~W} \mathrm{~m}^{-1} \mathrm{~K}^{-1}\right)$, was used as an intermediate layer to maintain the thermal gradient across the TEC. First, the Si wafer was dry etched (hole diameter $=0.5 \mathrm{~mm}$ ) using high rate (800 W coil power, passivation gas: $\mathrm{C}_{4} \mathrm{~F}_{8} 140 \mathrm{sccm}$ flow, etching gas: $\mathrm{SF}_{6} 140 \mathrm{sccm}$ flow, pressure 3.7-9 $\mathrm{Pa}$ ) deep reactive ion etching (RIE) (refer to Fig. 5(b and c)) after the photolithography process (refer to Fig. 5(a and b)) using OFPR $300 \mathrm{cp}$ as the positive photo resist mask (refer to Fig. $5(\mathrm{a}-\mathrm{c})$ ). A hole was made as an inlet for the TEC device. Next, the Si wafer with the hole as the upper electrode, and a Si wafer without a hole as the lower electrode, were sputtered using a SHIBAURA sputter machine to deposit a Ti layer with a thickness of $23.6 \mathrm{~nm}$ (refer to Fig. 5(d)) and a Pt layer with a thickness of $420 \mathrm{~nm}$ as the redox active area. The opposite side of the Si wafer was deposited with an Au layer of thickness $120 \mathrm{~nm}$ which also connected to the side of the Si wafer as a Pt-Au electrical contact (refer to Fig. 5(e)). As shown in Fig. 5(f), the upper and lower electrodes were

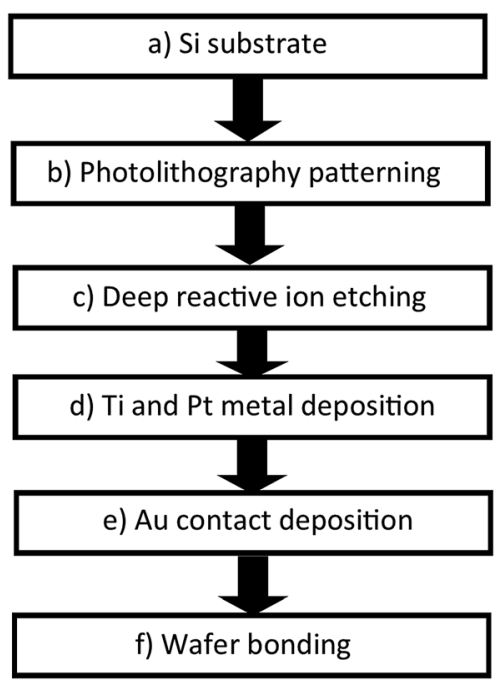

Fig. 4 TEC device fabrication process flow.
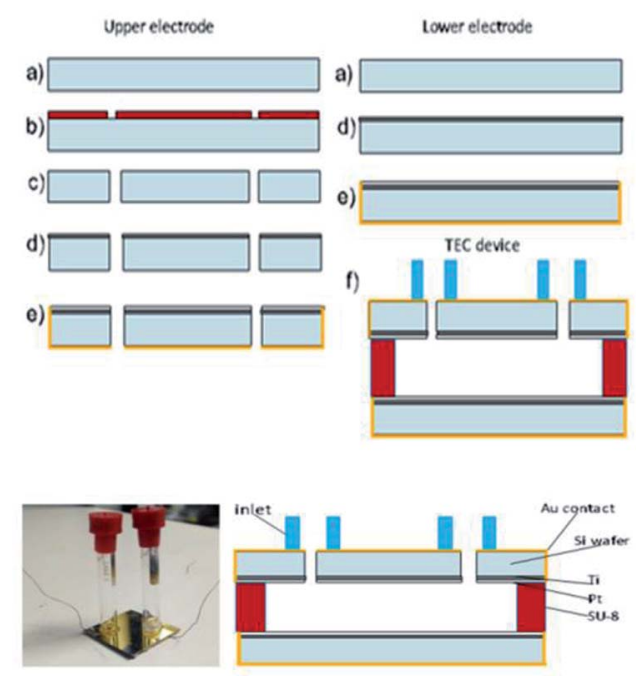

Fig. 5 TEC device fabrication process.

assembled using a patterned $300 \mu \mathrm{m}$ thickness SU-8 dry film resist to obtain a $300 \mu \mathrm{m}$ electrode separation, and using 4 layers of SU-8 dry film to obtain a $1 \mathrm{~mm}$ electrode separation. The SU-8 dry film was laminated first for each layer on the lower electrode at a temperature of $65{ }^{\circ} \mathrm{C}$ for 5 minutes (soft bake) before both the upper and the lower electrodes were clamped and heated in the furnace at $95{ }^{\circ} \mathrm{C}$ for 1 hour (hard baked wafer bonding process). For ease of TEC material filling, $1 \mathrm{~cm}$ of a Pyrex glass tube with a $5 \mathrm{~mm}$ diameter inlet was bonded to the hole on the Si wafer as the inlet and a rubber cap was used to enclose the inlet after the filling process. The filling process was done in vacuum conditions using a glove box to avoid the formation of micro bubbles inside the TEC device.

\section{Results and discussion}

\section{Ligand 16 characterisation}

The results of CHN elemental analyses of the ligand $(76.0 \% \mathrm{C}$; $13.1 \% \mathrm{H} ; 3.9 \% \mathrm{~N})$ were in good agreement with those calculated for the empirical formula $\mathrm{C}_{12} \mathrm{H}_{37} \mathrm{NO}(76.5 \% \mathrm{C} ; 12.6 \% \mathrm{H} ; 3.3 \% \mathrm{~N}$; formula weight $337.52 \mathrm{~g} \mathrm{~mol}^{-1}$ ). Fig. 6 shows the ${ }^{1} \mathrm{H}-\mathrm{NMR}$ spectrum for $\mathbf{L 1 6}$ in which the assignments for the ligand structure are labelled based on the integral of the observed chemical shifts.

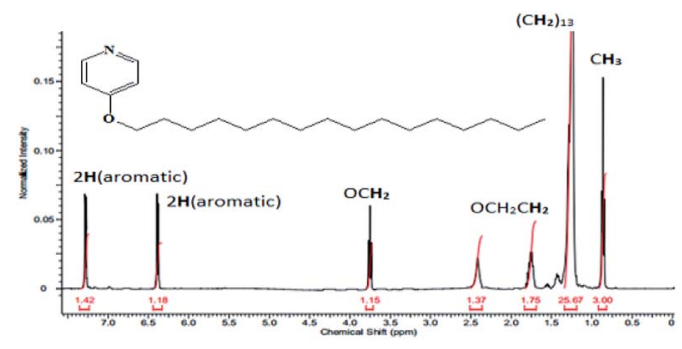

Fig. $6{ }^{1} \mathrm{H}-\mathrm{NMR}$ spectrum of L16 at room temperature. 


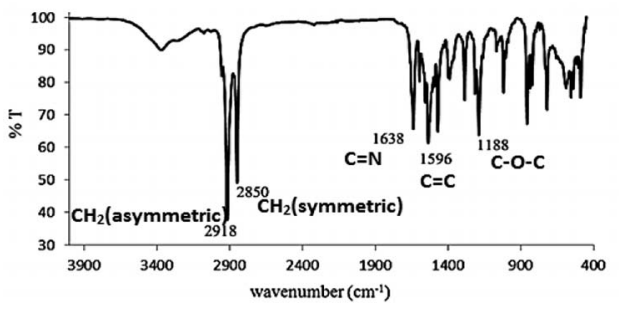

Fig. 7 FTIR analysis of L16 at room temperature.

The FTIR spectrum of L16 in Fig. 7 shows two strong peaks at $2918 \mathrm{~cm}^{-1}$ and $2850 \mathrm{~cm}^{-1}$ for $\mathrm{CH}_{2}$ asymmetric and symmetric stretching, respectively, while strong peaks at $1638 \mathrm{~cm}^{-1}$, $1596 \mathrm{~cm}^{-1}$ and $118 \mathrm{~cm}^{-1}$ are assigned to aromatic $\mathrm{C}=\mathrm{N}, \mathrm{C}=\mathrm{C}$ and $\mathrm{C}-\mathrm{O}-\mathrm{C}$ stretching, respectively, in good agreement with the structural formula of $\mathbf{L 1 6}$ as deduced from the CHN elemental analyses and ${ }^{1} \mathrm{H}-\mathrm{NMR}$.

\section{Preparation of Fe, Mn and Co complexes}

The formulae for the complexes with the new chain ligand $\mathbf{L 1 6}$ were deduced as shown in Table 1; the complexes with ligand L14 have been described in our previous work. ${ }^{9}$

$\left[\mathrm{Co}(\right.$ cyclam $\left.)(\mathbf{L 1 6})_{2}\right]\left(\mathrm{C}_{6} \mathrm{H}_{5} \mathrm{COO}\right)_{3} \cdot 4 \mathrm{H}_{2} \mathrm{O}$ whose chemical formula was based on the results of elemental analyses $(65.7 \%$ $\mathrm{C} ; 9.5 \% \mathrm{H} ; 6.0 \% \mathrm{~N}$ ), was consistent with the chemical formula $\mathrm{CoC}_{73} \mathrm{H}_{121} \mathrm{~N}_{6} \mathrm{O}_{12}(65.7 \% \mathrm{C} ; 9.1 \% \mathrm{H} ; 6.3 \% \mathrm{~N}$; formula weight, $\left.1333.71 \mathrm{~g} \mathrm{~mol}^{-1}\right)$.

For $\left[\mathrm{Fe}(\right.$ cyclam $\left.\left.)(\mathbf{L 1 6})_{2}\right]\left(\mathrm{C}_{6} \mathrm{H}_{5} \mathrm{COO}\right)_{3}\right] \cdot 4 \mathrm{H}_{2} \mathrm{O}$, the CHN analyses $(65.3 \% \mathrm{C} ; 10.0 \% \mathrm{H} ; 6.0 \% \mathrm{~N})$ were in good agreement with those calculated for $\mathrm{C}_{73} \mathrm{H}_{121} \mathrm{FeN}_{6} \mathrm{O}_{12}(65.9 \% \mathrm{C} ; 9.2 \% \mathrm{H} ; 6.3 \% \mathrm{~N}$; formula weight, $\left.1330.6 \mathrm{~g} \mathrm{~mol}^{-1}\right)$.

The elemental analyses of $\left[\mathrm{Mn}(\right.$ cyclam $\left.)(\mathbf{L 1 6})\left(\mathrm{H}_{2} \mathrm{O}\right)\right]\left(\mathrm{C}_{6} \mathrm{H}_{5^{-}}\right.$ $\mathrm{COO})_{3} \cdot 3 \mathrm{H}_{2} \mathrm{O}(61.2 \% \mathrm{C} ; 8.8 \% \mathrm{H} ; 6.4 \% \mathrm{~N})$ were in good agreement with those calculated for the chemical formula $\mathrm{C}_{52} \mathrm{H}_{84} \mathrm{MnN}_{5} \mathrm{O}_{11}(61.8 \% \mathrm{C} ; 8.4 \% \mathrm{H} ; 6.9 \% \mathrm{~N}$; formula weight, $1010.2 \mathrm{~g} \mathrm{~mol}^{-1}$ ).

It was found from the CHN elemental analyses that the newly synthesised complexes had a difference in the number of mol of bound lattice water and number of mol of benzoate $\left(\mathrm{C}_{6} \mathrm{H}_{5} \mathrm{COO}^{-}\right)$counter ions compared to those found in our previous study, which suggested that the valence charges of the complexes were metal $2+$ and metal $3+$ for $\mathbf{L 1 4}$ and $\mathbf{L 1 6}$ respectively. The actual binding modes of a $\mathrm{RCOO}^{-}$ion were inferred from FTIR spectroscopy, as shown in Fig. 8, based on

Table 1 Formulae of complexes

\begin{tabular}{lll}
\hline No. & Complex & Ref. \\
\hline 1 & {$\left[\mathrm{Fe}(\right.$ cyclam $\left.)(\mathbf{L 1 4})_{2}\right]\left(\mathrm{C}_{6} \mathrm{H}_{5} \mathrm{COO}\right)_{2} \cdot 2 \mathrm{H}_{2} \mathrm{O}$} & 9 \\
2 & {$\left[\mathrm{Fe}(\right.$ cyclam $\left.)(\mathbf{L 1 6})_{2}\right]\left(\mathrm{C}_{6} \mathrm{H}_{5} \mathrm{COO}\right)_{3} \cdot 4 \mathrm{H}_{2} \mathrm{O}$} & This study \\
3 & {$\left[\mathrm{Co}(\right.$ cyclam $\left.)(\mathbf{L 1 4})_{2}\right]\left(\mathrm{C}_{6} \mathrm{H}_{5} \mathrm{COO}\right)_{2} \cdot 3 \mathrm{H}_{2} \mathrm{O}$} & 9 \\
4 & {$\left[\mathrm{Co}(\right.$ cyclam $\left.)(\mathbf{L 1 6})_{2}\right]\left(\mathrm{C}_{6} \mathrm{H}_{5} \mathrm{COO}\right)_{3} \cdot 4 \mathrm{H}_{2} \mathrm{O}$} & This study \\
5 & {$\left[\mathrm{Mn}(\right.$ cyclam $\left.)(\mathbf{L 1 4})_{2}\right]\left(\mathrm{C}_{6} \mathrm{H}_{5} \mathrm{COO}\right)_{2} \cdot 4 \mathrm{H}_{2} \mathrm{O}$} & 9 \\
6 & {$\left[\mathrm{Mn}(\right.$ cyclam $\left.)(\mathbf{L 1 6})\left(\mathrm{H}_{2} \mathrm{O}\right)\right]\left(\mathrm{C}_{6} \mathrm{H}_{5} \mathrm{COO}\right)_{3} \cdot 3 \mathrm{H}_{2} \mathrm{O}$} & This study
\end{tabular}

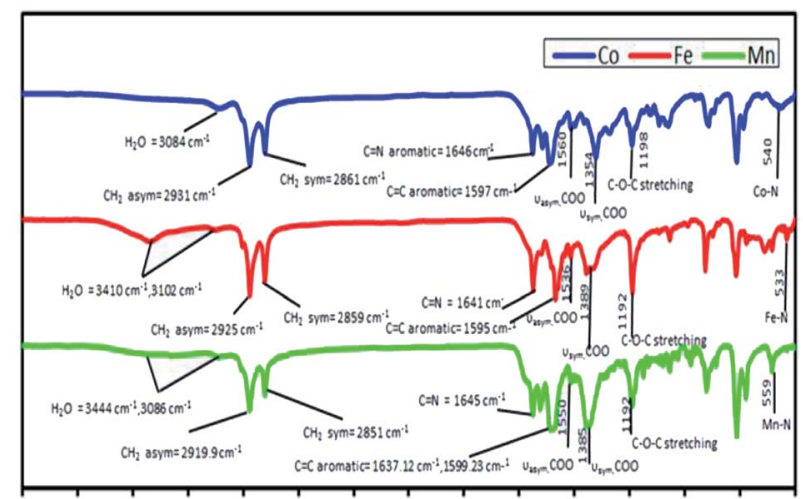

$395037003450320029502700245022001950170014501200 \quad 950 \quad 700 \quad 450$ Wave number $\left[\mathrm{cm}^{-1}\right]$

Fig. 8 FTIR of metal complexes of L16 at room temperature.

the difference $(\Delta)$ in the values of the asymmetric vibration of the COO group ( $\left.v_{\text {asym }}\right)$ and the symmetric vibration of the COO group $\left(v_{\mathrm{sym}}\right)$, where $\Delta_{\mathrm{COO}}=206 \mathrm{~cm}^{-1}, \Delta_{\mathrm{COO}}=147 \mathrm{~cm}^{-1}$ and $\Delta_{\mathrm{COO}}=183 \mathrm{~cm}^{-1}$ for $\mathrm{Co}$, Fe and Mn complexes, respectively. Thus, it is suggested that a free (non-coordinated) $\mathrm{C}_{6} \mathrm{H}_{5} \mathrm{COO}^{-}$ ion binding mode exists for the complexes.

\section{Thermal properties}

The motivation for the thermal analysis was to demonstrate the feasibility of the ionic $\mathbf{L 1 6}$ complexes for a real-life application of low-waste heat energy harvesting (below $100{ }^{\circ} \mathrm{C}$ ).

Fig. 9 shows the measured mass loss of the complexes as a function of temperature. The complexes were found to be stable in the temperature range $300-400 \mathrm{~K}$. Thus, we inferred that the complexes would be stable for TEC application in the temperature range 300-400 K. From TGA, the decomposition temperatures of the complexes were $420 \mathrm{~K}, 417 \mathrm{~K}$ and $413 \mathrm{~K}$ for $\mathrm{Co}, \mathrm{Fe}$ and $\mathrm{Mn}$, respectively, due to the loss of latticecoordinated $\mathrm{H}_{2} \mathrm{O}$.

Fig. 10 shows DSC scans for the $\mathbf{L 1 6}$ complexes recorded in one successive heating-cooling cycle within the temperature range $300-392 \mathrm{~K}$, which is below the TGA weight loss temperatures. Co showed a strong endothermic peak at $318 \mathrm{~K}(\Delta H=$ $+93.1 \mathrm{~kJ} \mathrm{~mol}^{-1}$ ) which was assigned to its melting temperature. Upon cooling, there was a weak exothermic peak at $328 \mathrm{~K}(\Delta H=$ $\left.-1.17 \mathrm{~kJ} \mathrm{~mol}^{-1}\right)$. The $\mathrm{Mn}$ complex showed three endothermic peaks at onset (i) $\left(T=303 \mathrm{~K}, \Delta H=+13.6 \mathrm{~kJ} \mathrm{~mol}^{-1}\right)$, (ii) $(T=321$ $\left.\mathrm{K}, \Delta H=+1.0 \mathrm{~kJ} \mathrm{~mol}^{-1}\right)$ and (iii) $\left(T=348 \mathrm{~K}, \Delta H=+1.1 \mathrm{~kJ} \mathrm{~mol}^{-1}\right)$. Upon cooling, only one exothermic peak at (i) $(T=318 \mathrm{~K}, \Delta H=$ $-1.1 \mathrm{~kJ} \mathrm{~mol}^{-1}$ ) was evident. Fe showed a strong and broad endothermic peak at $328 \mathrm{~K}\left(\Delta H=+112.1 \mathrm{~kJ} \mathrm{~mol}^{-1}\right)$ which was assigned to the breaking of strong bonds. Upon cooling, there was only one exothermic peak at (i) $(T=323 \mathrm{~K}, \Delta H=$ $-2 \mathrm{~kJ} \mathrm{~mol}^{-1}$ ). Thus, Fe showed the highest thermal stability followed by Co and then Mn. These observations can be correlated to the fact that the FeL16 complex is the most stable diamagnetic complex and hence provides the largest entropy change accompanying the spin state transition and 


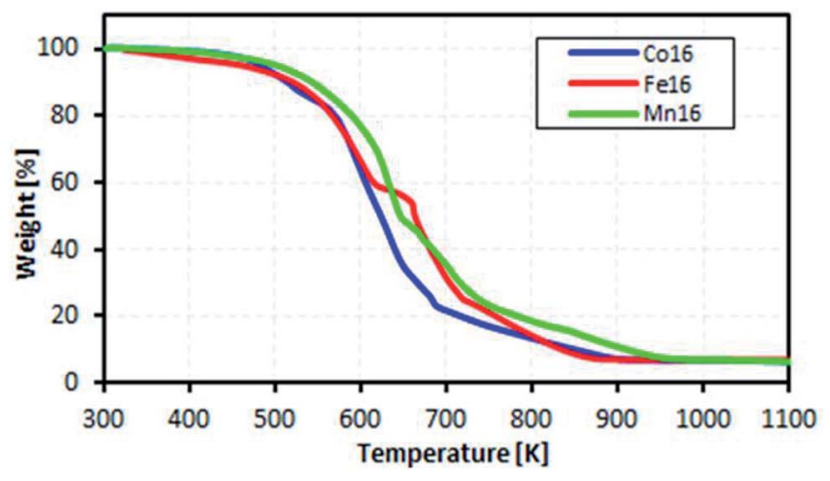

Fig. 9 TGA of the complexes.

correspondingly, the highest Seebeck coefficient. Notably, there is a strong difference between its endothermic peak and exothermic peak. This will have significance for applications since the complex will absorb heat as convection at the cold side of the TEC when it is heated, which will aid the completion of the redox cycle in the TEC and generate a high entropy difference, thus increasing the Seebeck coefficient. The entropy differences $\Delta S$ calculated from the differences of the endothermic and exothermic entropy changes for FeL16, CoL16 and MnL16 were $0.34,0.29$ and $0.04834 \mathrm{~kJ} \mathrm{~mol}^{-1} \mathrm{~K}^{-1}$, respectively, thus showing that Fe gave the highest $\Delta S$ when compared to the Co and Mn complexes. From the calculated entropy we deduced that the magnitude of $S_{\mathrm{e}}$ generated as a function of transition metal type would follow the order Fe > $\mathrm{Co}>\mathrm{Mn}$. It was also found that the heat capacity change for the endothermic-exothermic transition for Fe was the highest at $16.14 \mathrm{~kJ} \mathrm{~mol}^{-1}$ followed by $\mathrm{Co}$ at $7 \mathrm{~kJ} \mathrm{~mol}^{-1}$ and $\mathrm{Mn}$ at $0.96 \mathrm{~kJ} \mathrm{~mol}^{-1}$.
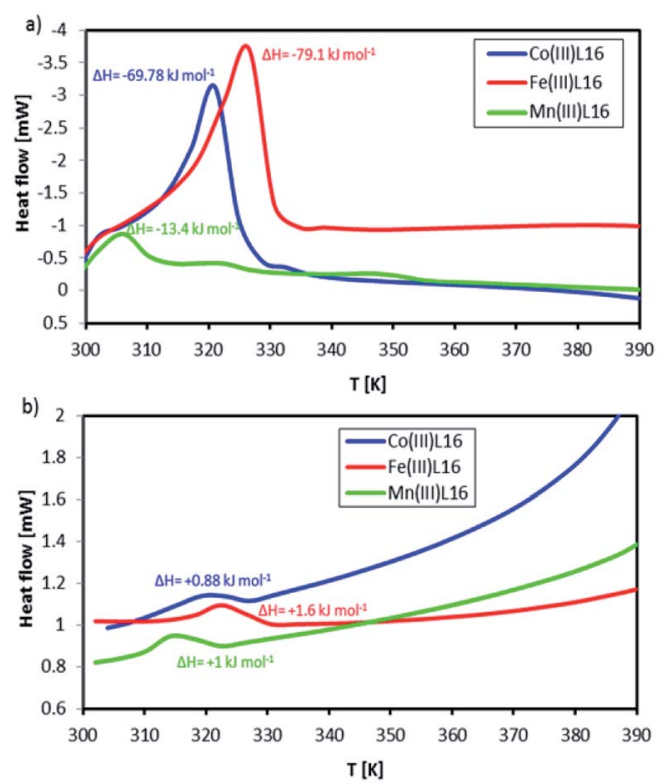

Fig. 10 DSC scans for (a) heating, and (b) cooling of the L16 complexes.

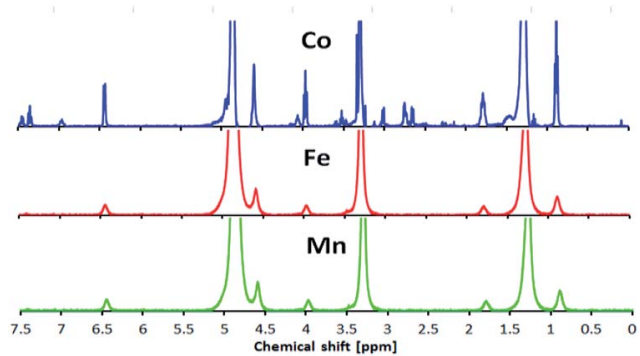

Fig. $11{ }^{1} \mathrm{H}$-NMR spectra of the Co, Fe and Mn L16 complexes at room temperature.

\section{Magnetic properties}

Fig. 11 shows ${ }^{1} \mathrm{H}-\mathrm{NMR}$ spectra for the Co, Mn and Fe complexes at room temperature. The Co complex showed a peak for the organic ligand, suggesting that it was a diamagnetic complex $\left({ }^{3} \mathrm{~d}_{6}\right.$; LS $)$. However, Fe and Mn showed several broad peaks which indicated paramagnetism at room temperature.

The temperature dependence of the SQUID magnetometry measurements was analysed, as shown in Fig. 12. At room temperature $(298 \mathrm{~K})$, the Co complex showed diamagnetic (LS) behaviour $\left(\chi_{\mathrm{M}} T=-0.314 \mathrm{~cm}^{3} \mathrm{~K} \mathrm{~mol}^{-1}\right)$ while Fe $\left(\chi_{\mathrm{M}} T=+0.14\right.$ $\left.\mathrm{cm}^{3} \mathrm{~K} \mathrm{~mol}^{-1}\right)$ and $\mathrm{Mn}\left(\chi_{\mathrm{M}} T=+14.7 \mathrm{~cm}^{3} \mathrm{~K} \mathrm{~mol}^{-1}\right)$ were paramagnetic; this was in good agreement with the magnetism of the complexes at room temperature found from ${ }^{1} \mathrm{H}-\mathrm{NMR}$. All complexes showed a HS to LS transition with increasing temperature due to the breaking of the van der Waals forces between the alkyl chains which allowed for a closer approach of the ligand to the metal centre, so driving a more stable LS state. $^{30}$ The Mn complex showed paramagnetic behaviour over the temperature range 298-390 K suggesting a high Jahn-Teller distortion of the HS-LS transition. Interestingly, the paramagnetic Fe was shown to change to a stable diamagnetic $\left(\chi_{\mathrm{M}} T\right.$ $=-3.31 \mathrm{~cm}^{3} \mathrm{~K} \mathrm{~mol}^{-1}$ ) state at the transition temperature of $T=$ $350 \mathrm{~K}$. Co showed a two-step LS state transition at the temperature of $303 \mathrm{~K}$ for LS (i) and at the temperature of $373 \mathrm{~K}$ for LS (ii), which was expected due to the loss of the $\mathrm{H}_{2} \mathrm{O}$ lattice bonding upon heating. Hence, it was inferred that in solution, the $\mathrm{Fe}$ and Co complexes formed a stable LS state in ionic form due to the solvation of the $\mathrm{H}_{2} \mathrm{O}$ lattice. A further investigation into the temperature dependent $\mathrm{UV}$-vis properties is presented in the next section to investigate the SCO effect of the complexes in solution.

\section{UV-vis properties}

The motivation for performing UV-vis spectroscopy was to confirm the octahedral structure of the complexes through their absorption spectra. The UV-vis spectra are shown in Fig. 13. The Co complex continuously increased in absorbance from $800 \mathrm{~nm}$ to the shoulder of a d-d band (due to the electronic transition from ${ }^{1} \mathrm{~A}_{1 \mathrm{~g}}$ to ${ }^{1} \mathrm{~T}_{1 \mathrm{~g}}$ for a LS octahedral $\mathrm{Co}$ (III) complex) at about $550 \mathrm{~nm}$ and showed a charge transfer (CT) band at about $286 \mathrm{~nm}$. Fe showed continuously increasing absorbance from $700 \mathrm{~nm}$ to a shoulder at $289 \mathrm{~nm}$ which was proposed for the 


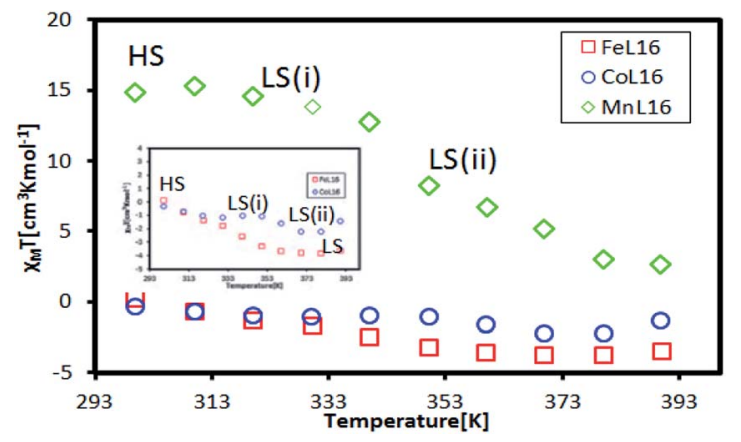

Fig. 12 Temperature dependent SQUID magnetometry analysis of the L16 complexes.

overlapping electronic transitions from ${ }^{2} \mathrm{~T}_{2 g}$ to ${ }^{2} \mathrm{~A}_{2 g},{ }^{2} \mathrm{~T}_{1 g},{ }^{2} \mathrm{E}_{\mathrm{g}}$ and ${ }^{2} \mathrm{~T}_{2 \mathrm{~g}}$ for an octahedral LS Fe(III) complex. The Mn complex showed the same CT band as the Co complex; the absorbance increased continuously from $850 \mathrm{~nm}$ to a shoulder at $307 \mathrm{~nm}$ suggesting an octahedral LS Mn(III) complex.

This work was extended by conducting molar absorption $(\varepsilon)$ analysis as a function of temperature to understand the $\mathrm{SCO} /$ reverse SCO capability and reversibility behaviour of the complexes when they became ionic complexes in solution. The absorption spectra of the $\mathrm{Fe}(\mathrm{III}) \mathbf{L 1 6}, \mathrm{Mn}$ (III)L16 and $\mathrm{Co}(\mathrm{III}) \mathbf{L 1 6}$ complexes in solution at different temperatures are shown in Fig. 14. The spectra clearly show the change in intensities of the spin allowed transitions, due to the HS to LS transitions and vice versa. The $\varepsilon$ values $\left(863 \mathrm{M}^{-1} \mathrm{~cm}^{-1}\right)$ remained unchanged for the Co(III)L16 complex in solution in the first heating cycle within the temperature range 300-305 $\mathrm{K}$. Then, after $305 \mathrm{~K}$, the molar absorption decreased to $645 \mathrm{M}^{-1} \mathrm{~cm}^{-1}$ and remained unchanged upon further heating to $343 \mathrm{~K}$. Upon cooling and reheating, the molar absorption remained unchanged showing that the $\mathrm{Co}(\mathrm{III}) \mathbf{L 1 6}$ complex could not change to a LS state once it had become HS. Thus the Co(III)L16 complex showed an irreversible SCO behaviour in solution (LS to HS on heating). Due to this irreversible SCO behaviour, a HS state of Co(III)L16 in TEC was proposed for both oxidation and reduction after heating. Thus the complex is expected to suffer only weak Jahn-Teller distortions in contrast to the previous ${ }^{9} \mathrm{Co}(\mathrm{II}) \mathbf{L} 14$ which suffered

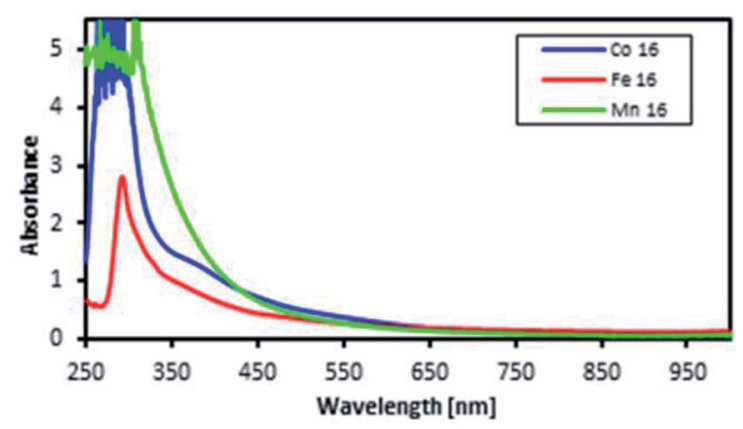

Fig. 13 UV-vis spectra of the L16 complexes at room temperature.
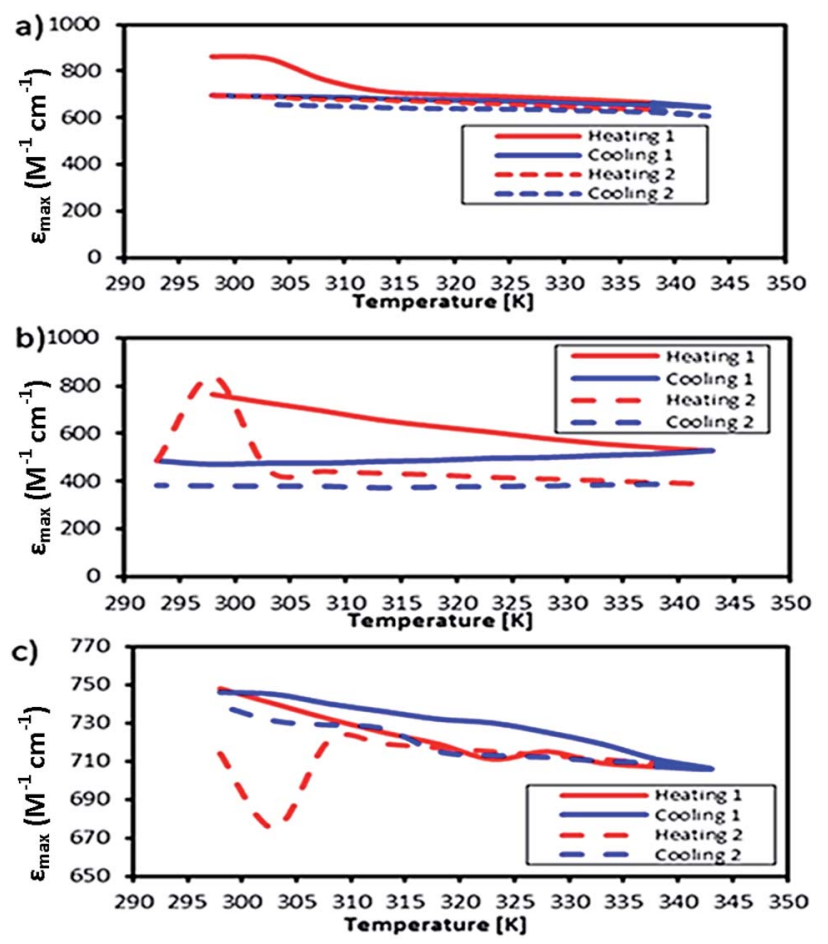

Fig. 14 Temperature dependent molar absorption values of (a) Co, (b) $\mathrm{Fe}$, and (c) Mn complexes in solution.

weak Jahn-Teller distortions for LS Co(II)L14 complexes and strong distortions for $\mathrm{HS} \mathrm{Co(III)L14} \mathrm{(refer} \mathrm{to} \mathrm{Fig.} \mathrm{2).}$

The Fe(III)L16 complex showed decreased molar absorption values from $764 \mathrm{M}^{-1} \mathrm{~cm}^{-1}$ to $528 \mathrm{M}^{-1} \mathrm{~cm}^{-1}$ upon heating from $300 \mathrm{~K}$ to $343 \mathrm{~K}$. Upon cooling, the molar absorption gradually decreased further to $471 \mathrm{M}^{-1} \mathrm{~cm}^{-1}$ and then remained constant within the temperature range 300-294 K. Upon reheating, the value of $\varepsilon$ abruptly increased to $840 \mathrm{M}^{-1} \mathrm{~cm}^{-1}$ at $298 \mathrm{~K}$ and then decreased abruptly to $441 \mathrm{M}^{-1} \mathrm{~cm}^{-1}$ and $388 \mathrm{M}^{-1} \mathrm{~cm}^{-1}$ at $308 \mathrm{~K}$ and $343 \mathrm{~K}$, respectively. Thus, the Fe(III)L16 complex was inferred to exhibit normal SCO behaviour with a LS to HS transition on heating and a reverse SCO (HS to LS) on cooling in solution. Upon reheating, the Fe(III)L16 demonstrated re-entrant behaviour (HSLS-HS) transitions at $303 \mathrm{~K}$. Thus, Fe(III)L16 showed reversible SCO and reverse SCO behaviour due to the good thermal stability (consistent with the significant endothermic peak found in the DSC analysis) of the long alkyl chain ligand. The Fe(III)L16 complex in TEC was proposed to have both molecular stability at the cold side $\left(\mathrm{LS} \mathrm{Fe}^{2+}\right.$ ) and the hot side ( $\mathrm{HS} \mathrm{Fe}^{3+}$ ) (refer to Fig. 2). Compared to the previous ${ }^{9} \mathrm{Fe}(\mathrm{II}) \mathbf{L} \mathbf{1 4}$ complex that suffered a weak distortion $\left(\mathrm{HS} \mathrm{Fe}^{2+}\right.$ ) upon heating, the $\mathrm{Fe}(\mathrm{III}) \mathbf{L} 16$ complex was not expected to suffer Jahn-Teller distortions while at the same time having a high potential to increase reaction entropy by having different spin states at the hot and cold sides due to the reversibility of its SCO behaviour.

Mn(III)L16 shows $\varepsilon$ values that gradually decreased to $705 \mathrm{M}^{-1} \mathrm{~cm}^{-1}$ upon heating. Upon cooling, the value of $\varepsilon$ gradually increased to $745 \mathrm{M}^{-1} \mathrm{~cm}^{-1}$ and then abruptly decreased to $706 \mathrm{M}^{-1} \mathrm{~cm}^{-1}$ at $343 \mathrm{~K}$. Upon second reheating, 
the values abruptly decreased to $676 \mathrm{M}^{-1} \mathrm{~cm}^{-1}$ at $303 \mathrm{~K}$ and then gradually increased to $729 \mathrm{M}^{-1} \mathrm{~cm}^{-1}$ at $308 \mathrm{~K}$. Upon second cooling from this temperature, the values gradually increased until $740 \mathrm{M}^{-1} \mathrm{~cm}^{-1}$ at $298 \mathrm{~K}$. Hence, the $\mathrm{Mn}$ complex showed re-entrant SCO behaviour in the first cooling mode between 303-298 K (HS-LS-HS) and upon second heating (LS-HS-LS) at 293-303 K. The Mn complex was inferred to exhibit reversible SCO behaviour in solution. Thus the Mn(III)L16 complex showed SCO and reverse SCO capability in the same way as the Fe(III)L16 complex, but the Mn(III) $\mathbf{L 1 6}$ complex possessed both weak distortions ( $\mathrm{LS} \mathrm{Mn}^{2+}$ ) and strong distortions ( $\mathrm{HS} \mathrm{Mn}^{3+}$ ) according to the Jahn-Teller rule (refer to Fig. 2) which is the same behaviour as shown by the previous ${ }^{9} \mathrm{Mn}(\mathrm{II}) \mathbf{L 1 4}$ complex. Thus, the $\mathrm{Mn}(\mathrm{III}) \mathbf{L 1 6}$ complex is not expected to show much difference in its Seebeck generation capability compared to the previous $\mathrm{Mn}$ (II) L14 complex.

\section{Seebeck coefficient}

This section quantifies the Seebeck generation capabilities of the optimised Fe, Mn and Co complexes in the presence of low molarity $(0.1 \mathrm{mM})$ reducing agent $\mathrm{KI}-\mathrm{KI}_{3}$ and supporting electrolyte TBATFB. Fig. 15 shows the Seebeck measurements of Mn, Co, and Fe L14 complexes (as reported previously ${ }^{9}$ ) and $\mathbf{L 1 6}$ complexes.

Fe shows a difference in the $S_{\mathrm{e}}$ sign which is positive for Fe(II) $\mathbf{L 1 4}$ and negative for Fe(III)L16. The Co complex shows a stable positive $S_{\mathrm{e}}$ for $\mathrm{Co}(\mathrm{III}) \mathbf{L} \mathbf{L}$ whilst $\mathrm{Co}(\mathrm{II}) \mathbf{L 1 4}$ shows a positive to negative $S_{\mathrm{e}}$ transition at $\Delta T=40 \mathrm{~K}$. Mn shows a positive $S_{\mathrm{e}}$ for
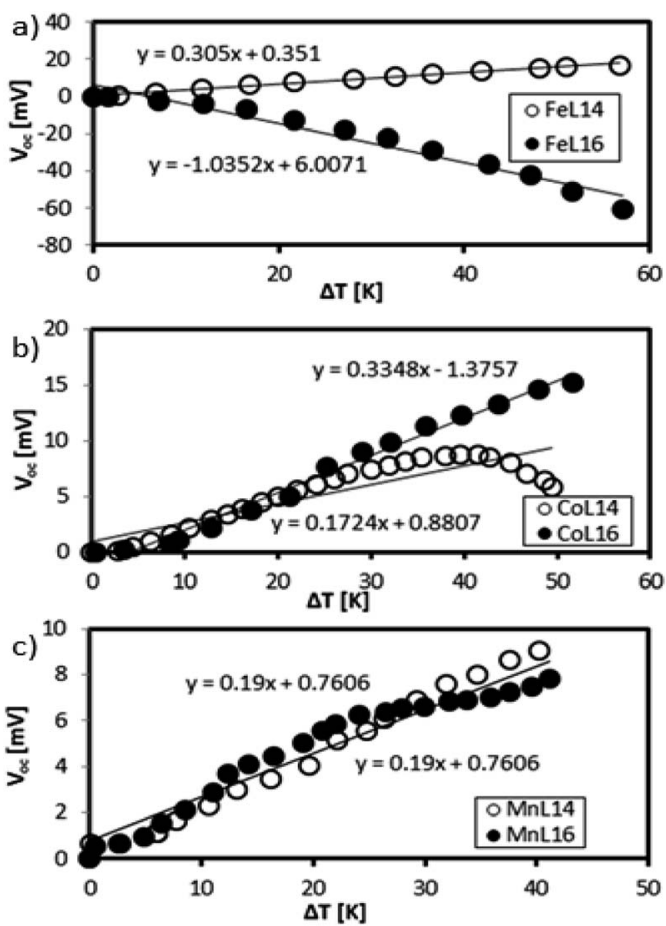

Fig. 15 Seebeck measurements of (a) Fe, (b) Co, and (c) $\mathrm{Mn}$ complexes. both $\mathrm{Mn}$ (II)L14 and Mn(III)L16. The positive sign is due to the dominance of reduction and the negative sign is due to the dominance of oxidation. ${ }^{13}$

The Fe(III)L16 complex, which was the most stable complex, showed the highest $S_{\mathrm{e}}$ magnitude $\left(-1 \mathrm{mV} \mathrm{K}^{-1}\right)$ followed by Co(III)L16 $\left(+0.3 \mathrm{mV} \mathrm{K}^{-1}\right)$ and $\mathrm{Mn}(\mathrm{III}) \mathbf{L 1 6}\left(0.6 \mathrm{mV} \mathrm{K}^{-1}\right)$. The increase of carbon chain length $\left(\mathrm{C}_{n}=\mathrm{C}_{14}\right)$ in the ligand design resulted in an improvement in $S_{\mathrm{e}}$ generation for Fe(III)L16 and $\mathrm{Co}(\mathrm{III}) \mathbf{L 1 6}$ which were 3.43 times and 1.94 times higher respectively compared to the Fe and Co L14 complexes (Fig. 15(a)). From the molecular Jahn-Teller distortion perspective, these enhancements are because the Fe and Co complexes possess stable molecular states in the LS-HS transition with applied temperature, thus increasing the entropy difference in the reaction. The strong distortion behaviour of the Mn complex, as expected, was not suitable for $S_{\mathrm{e}}$ generation for the TEC devices, and hence showed no enhancement of $S_{\mathrm{e}}$ value $\left(+0.19 \mathrm{mV} \mathrm{K}^{-1}\right.$ for both L14 and L16) (Fig. 15(b)).

From a thermodynamic perspective, the highest $S_{\text {e }}$ generation seen for the Fe complex was also due to the high heat capacity change and strong endothermic reaction that was shown by the DSC analysis. The stronger endothermic reaction of the Fe complex compared to the Co and Mn complexes was inferred to create strong convection at the hot side of the TEC device, hence increasing the entropy difference of the device. Thus, the highest entropy difference found for Fe followed by those for $\mathrm{Co}$ and $\mathrm{Mn}(0.34,0.29$ and $0.04834 \mathrm{~kJ} \mathrm{~mol}^{-1} \mathrm{~K}^{-1}$ respectively) obtained from the DSC analysis showed a significant correlation with the $S_{\mathrm{e}}$ generation capability in the TEC devices. The distortion behaviour of the Mn complex was not suitable for $S_{\mathrm{e}}$ generation in the TEC devices due to the reaction relaxation time, which shifted from high to low frequency, as found in our previous relaxation study. ${ }^{9}$

\section{Power density}

To prove the enhancement of TEC power generation by stability optimisation, a solution of the Fe(III)L16 complex was used to fill two fabricated TEC devices. The power density generated was compared with that generated by the less stable $\mathrm{Fe}(\mathrm{II}) \mathbf{L} \mathbf{1 4}$. The TEC devices had different electrode separations $(1 \mathrm{~mm}$ and 0.3 $\mathrm{mm}$ ). The temperature gradients observed for the TEC devices having $1 \mathrm{~mm}$ and $0.3 \mathrm{~mm}$ electrode separations were $\Delta T=5 \mathrm{~K}$ and $\Delta T=2 \mathrm{~K}$, respectively, where the temperature applied at the hot side was $305 \mathrm{~K}$ and the temperature at the cold side was maintained by air convection. Each TEC device was connected to a resistor box as load to measure the power output. All measurements were done at steady state with a constant temperature gradient. Fig. 16 shows that the maximum power density (active electrode area $=1 \mathrm{~cm}^{2}$ ) for the TEC device having the $1 \mathrm{~mm}$ electrode separation was 5 times higher than the power density generated by the TEC device having the $0.3 \mathrm{~mm}$ electrode separation. The maximum power density for the isothermal TEC device filled with stable Fe(III)L16 $\left(4.76 \mu \mathrm{W} \mathrm{m}^{-2}\right)$ in this study was proven to be higher than the maximum power density found for the less stable Fe(II)L14 $\left(2 \mu \mathrm{W} \mathrm{m}{ }^{-2}\right){ }^{9}$ 


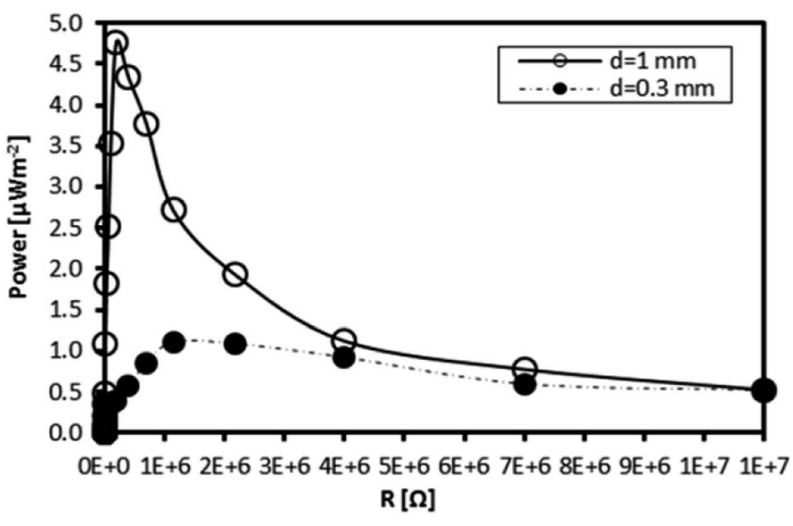

Fig. 16 Power output density of the Fe L16 complex at $\Delta T=5 \mathrm{~K}$ and $\Delta T=2 \mathrm{~K}$ for TEC devices with electrode separations of $1 \mathrm{~mm}$ and 0.3 $\mathrm{mm}$ respectively.

\section{Conclusions}

We have demonstrated $S_{\mathrm{e}}$ enhancement through the stability optimisation of metal complexes by modulating ligand length and thus Jahn-Teller distortions. The $S_{\mathrm{e}}$ of Co(III)L16 was 1.94 times higher than that of Co(II)L14 whilst the $S_{\mathrm{e}}$ of Fe(III)L16 was 3.43 times higher than that of $\mathrm{Fe}(\mathrm{II}) \mathbf{L 1 4}$. The enhancement of molecular stability through ligand optimisation enhanced $S_{\mathrm{e}}$ generation due to increased thermal stability, as shown from the strong endothermic peak in the DSC analysis. This was proven by the fact that no enhancement of $S_{\text {e }}$ generation was observed for the highly distorted Mn(II)L14 and Mn(III)L16 complexes. It was inferred that the high thermal stability was capable of enhancing natural convection and thus enhancing the entropy reaction in the TEC. Thus, this study gives a new perspective to the development of high $S_{\mathrm{e}}$ TEC materials through ligand design strategies which are based on the optimisation of octahedral structures and their magnetic properties.

\section{Conflicts of interest}

There are no conflicts to declare.

\section{Acknowledgements}

The authors thank the University of Malaya for the research grants FG009-17AFR, GPF022A/2018, PG142-2016A and RK009-2018.

\section{Notes and references}

1 H. Y. Zhou, T. Yamada and N. Kimizuka, J. Am. Chem. Soc., 2016, 138, 10502-10507.

2 T. J. Abraham, D. R. MacFarlane and J. M. Pringle, Chem. Commun., 2011, 47, 6260-6262.

3 H. Zhou and P. Liu, ACS Appl. Energy Mater., 2018, 1, 1424-1428. 4 S. Vassel and N. Vassel, Int. J. Heat Mass Transfer, 2017, 108, 2333-2337.

5 P. F. Salazar, S. Kumar and B. A. Cola, J. Appl. Electrochem., 2014, 44, 325-336.

6 E. V. Kuzminsky and O. A. Mashkin, Ukr. Khim. Zh., 1986, 52, 1055-1059.
7 H. Keppner, S. Uhl, E. Laux, L. Jeandupeux, J. Tschanz and T. Journot, Mater. Today: Proc., 2015, 2, 680-689.

8 J. T. Hupp and M. J. Weaver, Inorg. Chem., 1984, 23, 3639-3644. 9 M. M. I. M. Hasnan, N. Abdullah, S. M. Said, M. F. M. Salleh, S. A. M. Hussin and N. M. Shah, Electrochim. Acta, 2018, 261, 330-339.

10 N. Abdullah, N. L. M. Noor, A. R. Nordin, M. A. Halcrow, D. R. MacFarlane, M. A. Lazar, J. M. Pringle, D. W. Bruce, B. Donnio and B. Heinrich, J. Mater. Chem. C, 2015, 3, 2491-2499.

11 N. Abdullah, M. H. Elsheikh, N. M. J. N. Ibrahim, S. M. Said, M. F. M. Sabri, M. H. Hassan and A. Marlina, RSC Adv., 2015, 5, 50999-51007.

12 M. Peng, Z. Wen, M. Shao and X. Sun, J. Mater. Chem. C, 2017, 5, 7521-7526.

13 X. Niu, H. Zhu, X. Liang, Y. Guo, Z. Li and Y. Mai, Appl. Surf. Sci., 2017, 426, 1213-1220.

14 N. B. H. Mohamed, N. B. Brahim, R. Mrad, M. Haouari, R. B. Chaâbane and M. Negrerie, Anal. Chim. Acta, 2018, 1028, 50-58.

15 X. Ma, Q. Xiang, Y. Liao, T. Wen and H. Zhang, Appl. Surf. Sci., 2018, 457, 846-855.

16 G. Dai, H. Zou, X. Wang, Y. Zhou, P. Wang, Y. Ding, Y. Zhang, J. Yang and Z. L. Wang, ACS Photonics, 2017, 4, 2495-2503.

17 L. Cheng, Q. Xiang, Y. Liao and H. Zhang, Energy Environ. Sci., 2018, 11, 1362-1391.

18 T. J. Abraham, D. R. MacFarlane and J. M. Pringle, Energy Environ. Sci., 2013, 6, 2639-2645.

19 M. F. Dupont, D. R. MacFarlane and J. M. Pringle, Chem. Commun., 2017, 53, 6288-6302.

20 V. N. Sokolov, A. A. Pribochenko and L. P. Safonova, Russ. J. Electrochem., 2006, 42, 969-973.

21 Y. Katayama, S. Nakayama, N. Tachikawa and K. Yoshii, J. Electrochem. Soc., 2017, 164, H5286-H5291.

22 S. Hayami, Y. Komatsu, T. Shimizu, H. Kamihata and Y. N. Lee, Coord. Chem. Rev., 2011, 255, 1981-1990.

23 T. A. Siddique, S. Balamurugan, S. M. Said, N. A. Sairi and W. M. D. W. Normazlan, RSC Adv., 2016, 6, 18266-18278.

24 M. Inagaki, E. Itoh and A. Tanaka, Synth. Met., 1990, 35, 383-385. 25 S. W. Hasan, S. M. Said, M. F. M. Sabri, A. S. Abu Bakar, N. A. Hashim, M. M. I. M. Hasnan, J. M. Pringle and D. R. MacFarlane, Sci. Rep., 2016, 6.

26 A. Gunawan, H. C. Li, C. H. Lin, D. A. Buttry, V. Mujica, R. A. Taylor, R. S. Prasher and P. E. Phelan, Int. J. Heat Mass Transfer, 2014, 78, 423-434.

27 E. H. B. Anari, M. Romano, W. X. Teh, J. J. Black, E. Jiang, J. Chen, T. Q. To, J. Panchompoo and L. Aldous, Chem. Commun., 2016, 52, 745-748.

28 L. Aldous, J. J. Black, M. C. Elias, B. Gelinas and D. Rochefort, Phys. Chem. Chem. Phys., 2017, 19, 24255-24263.

29 N. Abdullah, N. L. M. Noor, A. R. Nordin, M. A. Halcrow, D. R. MacFarlane, M. A. Lazar, J. M. Pringle, D. W. Bruce, B. Donnio and B. Heinrich, J. Mater. Chem. C, 2015, 3, 2491-2499.

30 S. Hayami, Y. Shigeyoshi, M. Akita, K. Inoue, K. Kato, K. Osaka, M. Takata, R. Kawajiri, T. Mitani and Y. Maeda, Angew. Chem. Int. Ed., 2005, 44, 4899-4903. 